\title{
CONTROLLING THICKNESS VARIATION DURING PNEUMOTHERMAL FORMING IN THE SUPERPLASTIC REGIME
}

\author{
S. A. Osipov, ${ }^{1}$ V. V. Mironenko, ${ }^{1}$ \\ N. V. Maksimenko, ${ }^{1}$ and V. V. Kotov ${ }^{2}$
}

UDC 621.7 .04

Results are presented from the modeling of different methods of controlling thickness fluctuations in superplastic pneumothermal forming. Recommendations are given on the use of each method and a part made of titanium alloy VT-20 is used as an example to show the thickness distribution over the part for each method.

Keywords: pneumothermal forming of sheet parts, superplastic effect, control of thickness fluctuation.

Control of the change in the thickness of the semifinished product over the area of the part being formed is important in the pneumothermal forming of products in the superplastic regime. In individual cases, there is a limit to the reduction that can be made in the thickness of the semifinished product within certain zones of the surface of the part. Modeling of different versions of pneumothermal forming in the superplastic regime has shown that it is possible to control the change in thickness over the area of the part.

Several methods of superplastic pneumothermal forming were analyzed by using the example of the shaping of a base-type part with a thickness of $1 \mathrm{~mm}$. The base of the part included three structural elements of the boss type (Fig. 1).

The following simplified model of the material's behavior in the superplastic regime was used to perform the modeling [1]:

$$
\sigma=K \dot{\varepsilon}^{m},
$$

where $K$ is a proportionality factor; $\dot{\varepsilon}$ is the strain rate; $m$ is the strain-hardening modulus; and $\sigma$ is the stress.

The software package PAM-STAMP 2G, developed by the French company ESI Group, was used to model pneumothermal forming in the superplastic regime. Steel VT20 having the following parameters was chosen to analyze the formation of a part of the base type:

- Young's modulus - $112 \mathrm{GPa}$;

- Poisson's ratio - 0.333;

- density $-4.5 \cdot 10^{-6} \mathrm{~kg} / \mathrm{mm}^{3}$;

- proportionality factor $-0.597488 \mathrm{GPa}$;

- strain rate $-0.0016 \mathrm{sec}^{-1}[2]$; and

- strain-hardening modulus $-0.42[2]$.

\footnotetext{
${ }^{1}$ Irkutsk State Technical University, Irkutsk, Russia; e-mail: osipov_sa@istu.edu.

${ }^{2}$ Russian Division of the ESI Group; Yeltsin Ural Federal University (UrFU), Yekaterinburg, Russia.
}

Translated from Metallurg, No. 2, pp. 26-29, February, 2013. Original article submitted January 22, 2013. 


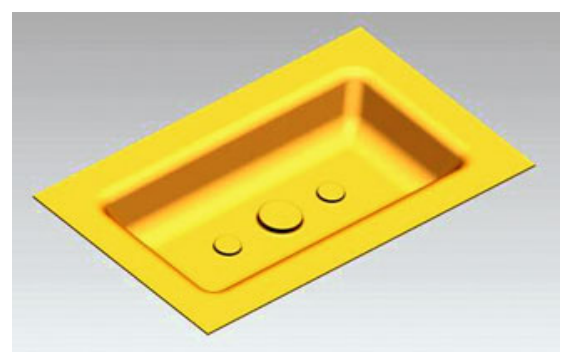

Fig. 1. A part of the base type.
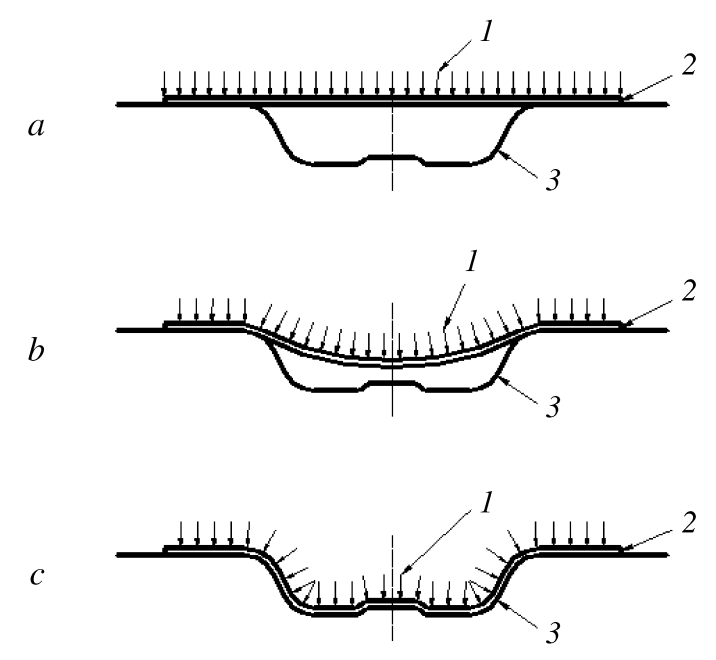

Fig. 2. Diagram of the method of pneumothermal forming (shaping):

1) pressure; 2) semifinished product; 3) die.

In all of the methods being discussed here, the semifinished product is shaped solely as a result of reductions in its thickness.

First method - shaping. In this case, pressure is exerted on the semifinished product from above and the die that replicates the contour of the part is below it (Fig. 2a). The part is deformed and assumes the shape of the die during the forming operation. This is the classical method of making parts by pneumothermal forming in the superplastic regime (Fig. $2 b$ and $c$ ).

The distribution of the thickness of the semifinished product was obtained by modeling the shaping process. The greatest thickness $(1 \mathrm{~mm})$ was found to exist in the flange of the part, while thickness was minimal $(0.55 \mathrm{~mm})$ at the corners of the base and the bosses. Thickness is minimal in these zones of the part because they are formed at the end of the process (Fig. 3).

The second method of pneumothermal forming in the superplastic regime is the formation of parts by the method of compression. The essence of this method is that the die corresponds to the contour of the part when it has been inverted. The method is otherwise similar to the shaping variant (Fig. 4). The part is shaped in such a way that its bottom is formed first. The second method is used when it is necessary to obtain a part having a bottom of maximum thickness and a flange of minimum thickness.

Modeling of the operation of forming by the compression method produces a part in which the thickest element is the bottom $(0.92 \mathrm{~mm})$ and the thinnest elements are the flanges $(0.18 \mathrm{~mm})$ (Fig. 5). The bottom of the part comes into contact with the die earlier in this scheme, so that its thickness changes less rapidly (due to the action of frictional forces) than in the zones where the semifinished product is freely shaped. 


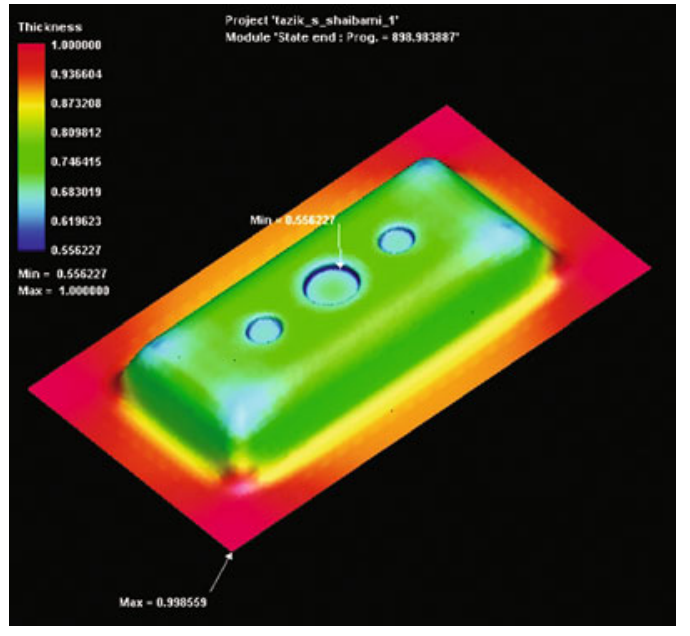

Fig. 3. Thickness distribution in pneumothermal forming (shaping).
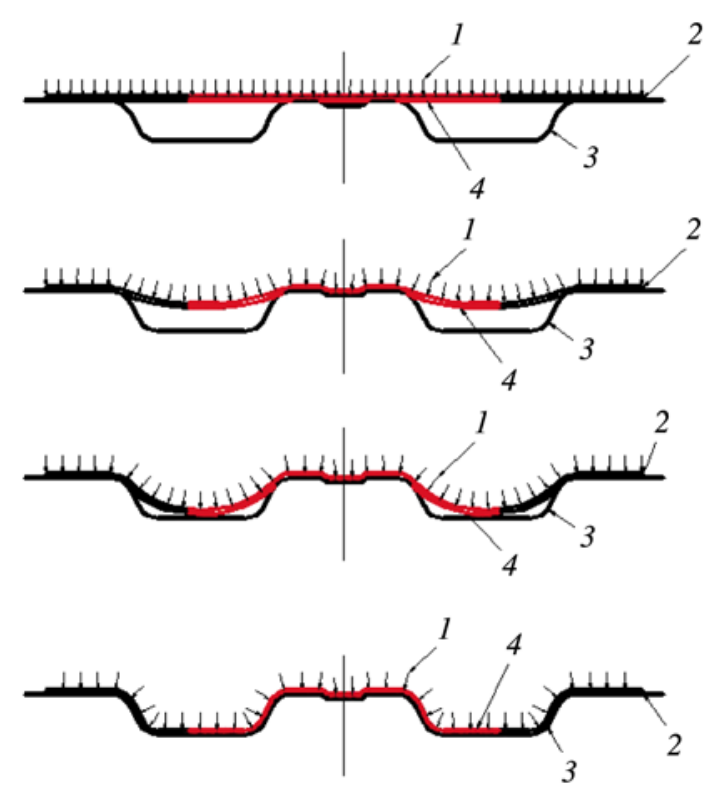

Fig. 4. Diagram of forming by compression: 1 ) pressure; 2) semifinished product; 3) die; 4) area of the part.

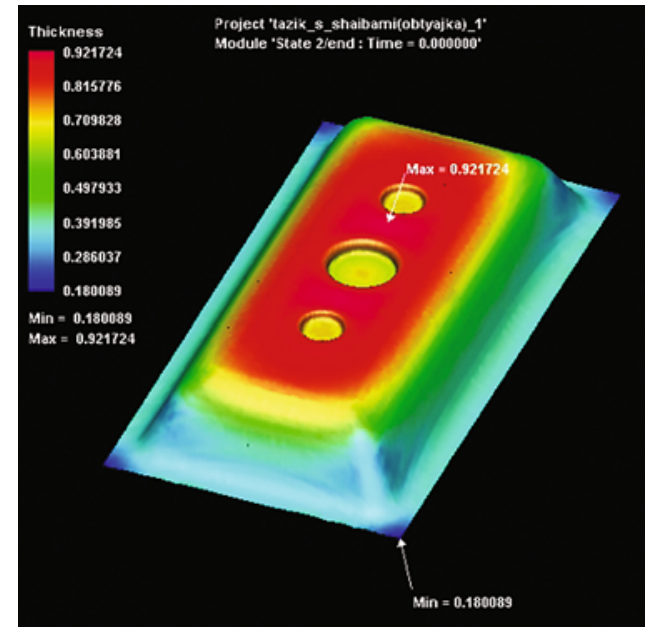

Fig. 5. Thickness distribution in forming by the compression method.

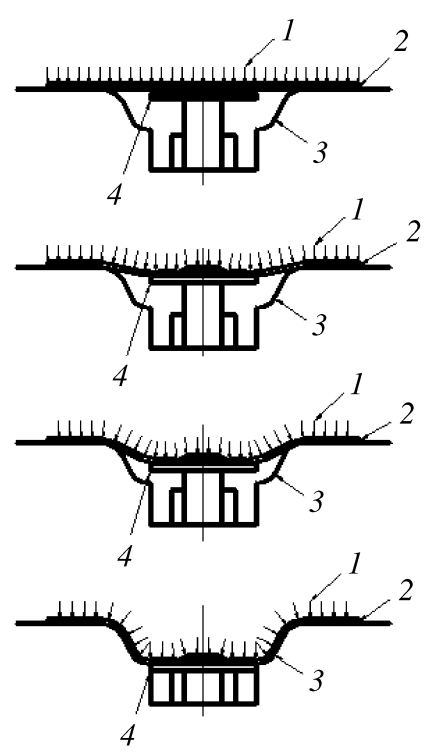

Fig. 6. Diagram of contact-area-based forming: 1) pressure; 2) semifinished product; 3) die; 4) moving part of the tooling.

The third method is based on the same phenomenon as the compression method. The only difference is that the product is shaped as a result of the action of a moving element rather than the form of the tooling. That element is always in contact with the semifinished product (Fig. 6). The third method is used when it is necessary to obtain a large thickness over a certain area of the part.

Modeling the contact-area-based forming scheme made it apparent that the thickness of the semifinished product in the region where it is contact with the moving element is equal to its original thickness. That thickness is identical over the entire area of contact and is limited by the area of the element (Fig. 7). The advantage of this method is that it is possible to 


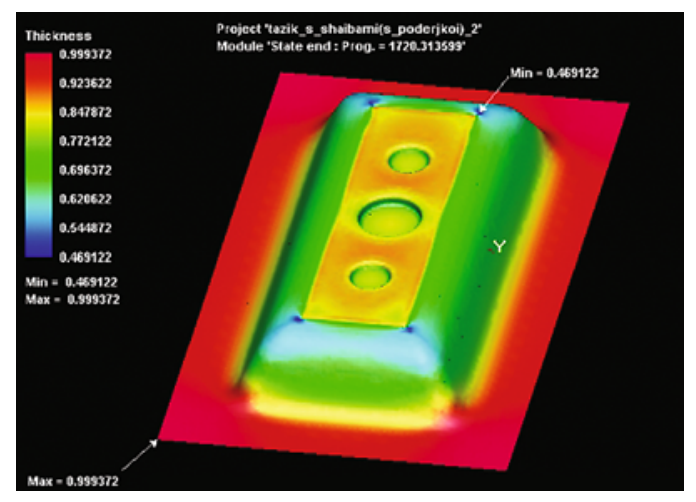

Fig. 7. Thickness distribution in contact-area-based forming: maximum thickness $-1 \mathrm{~mm}$; minimum thickness $-0.45 \mathrm{~mm}$.

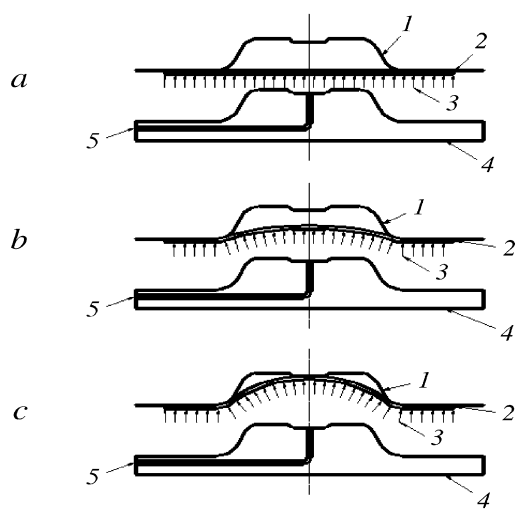

First step (acting pressure)

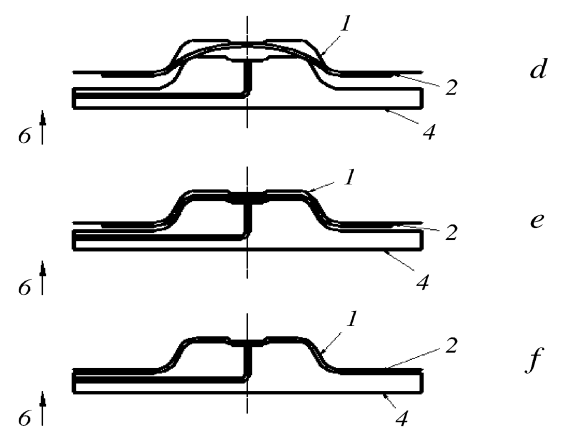

Second step (no pressure)

Fig. 8. Diagram of two-step forming: 1) die; 2) semifinished product; 3) pressure; 4) punch; 5) pressure application point; 6) punch motion vector.
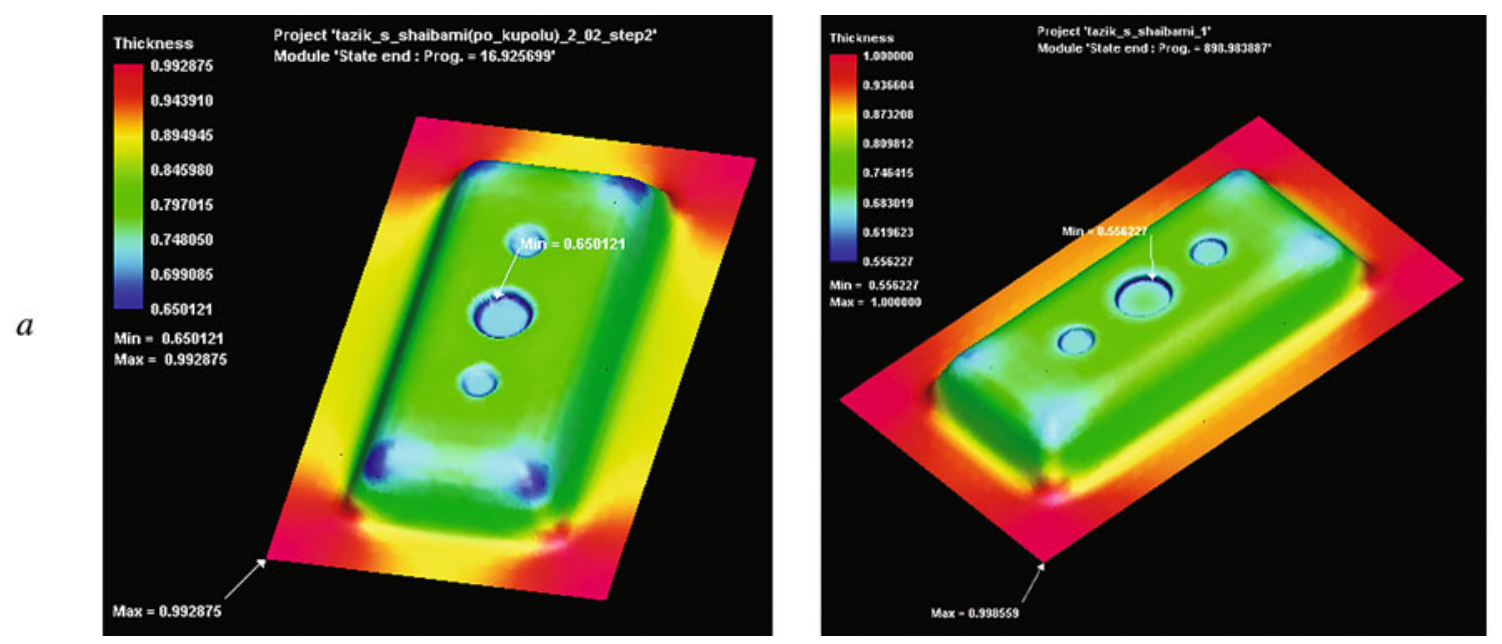

Fig. 9. Comparison of the distributions of the part's thickness in the two-step forming scheme $(a)$ and the shaping scheme $(b)$ : a) maximum thickness $-1 \mathrm{~mm}$; minimum thickness $-0.65 \mathrm{~mm} ; b$ ) maximum thickness $-1 \mathrm{~mm}$; minimum thickness $-0.55 \mathrm{~mm}$. 
assign different thicknesses to different zones. The method also makes it possible to vary the locations and dimensions of those zones.

The fourth method is a combination solution - two-step forming. On the whole, this method results in a better distribution of thickness over the entire area of the part. In the first step of the method, the semifinished product is freely (under the pressure of a gas) shaped in the die until contact is made with the first element of the part in accordance with the shaping scheme (Fig. $8 a-c$ ). In the second step, the part is formed as a result of movement of the punch to the die (Fig. $8 d-f$ ).

Modeling the forming operation in accordance with the two-step forming scheme made it possible to obtain a thickness distribution similar to that obtained in the shaping scheme but with one difference: the minimum thickness is $0.65 \mathrm{~mm}$, which is greater than the $0.55 \mathrm{~mm}$ realized for minimum thickness in the shaping scheme (Fig. 9). Thus, the level of thickness is greater over the entire area of a part that is formed by the combined-in-two-steps scheme. This forming method is recommended as an alternative to the shaping scheme, but the system overall and the design of the tooling more complicated in this case.

Conclusion. An analysis of the models that were obtained shows that there are sufficiently effective methods for controlling thickness variation in superplastic pneumothermal forming. The methods can act either locally or over large areas and in different zones to either preserve the initial thickness of the semifinished product or to make it thinner while maintaining the necessary level of strength in the chosen locations.

\section{REFERENCES}

1. E. N. Chumachenko, O. M. Smirnov, and M. A. Tsepin, Superplasticity: Materials, Theory, Technology [in Russian], KomKniga, Moscow (2005).

2. O. M. Smirnov, Metal-Shaping in the State of Superplasticity [in Russian], Mashinostroenie, Moscow (1979). 